\title{
Phacovitrectomy without preoperative steroids for rhegmatogenous retinal detachment with associated choroidal detachment
}

\author{
Junmin Gui ( $\nabla$ junmingui@163.com ) \\ Chongqing Aier-Mega Eye Hospital https://orcid.org/0000-0003-1905-9355 \\ Ling Ai \\ Chongqing Aier-Mega Eye Hospital \\ Ting Huang \\ Chongqing Aier-Mega Eye Hospital
}

\section{Research Article}

Keywords: Phacovitrectomy, retinal detachment, choroidal detachment, steroids

Posted Date: December 13th, 2018

DOI: https://doi.org/10.21203/rs.2.102/v1

License: (1) This work is licensed under a Creative Commons Attribution 4.0 International License. Read Full License 


\section{Abstract}

Background: To report the anatomical and visual outcomes of combined phacoemulsification and microinvasive pars plana vitrectomy (phacovitrectomy) without preoperative administration of steroids in the treatment of combined retinal detachments associated choroidal detachment(RRD/CD).

Methods: Medical records of patients who were diagnosed as RRD/CD without past ocular trauma and surgical history were retrieved and analyzed. All the patients were treated with phacovitrectomy plus silicone oil (SO) tamponade without preoperative steroids. Patients were followed up at least 3 months postoperatively. The mean follow-up time were $10.3 \pm 10.1$ months.

Results: Seventeen patients (17 eyes), 8 women and 9 men, met the including criteria with mean age of $60.4 \pm 8.4$ years. None of these eyes had intraocular lens implanted and none had combined scleral procedures in the primary surgical intervention. Preoperative B ultrasound showed that choroidal detachment was severe in 10 eyes (58.8\%), moderate in 2 eyes (11.8\%) and mild in 5 eyes(29.4\%). Fifteen eyes(82.4\%) had retina reattached after single operation. Of these 15 eyes, 14 eyes had SO removed, 8 of them had intraocular lens implanted, 2 eye had epimacular membrane peeling at the time of SO removing and one eye was refilled with SO. Two patients had retinal redetached within a month after primary surgical repair due to proliferation and would not willing to take re-operation. Fifteen eyes had postoperative visual acuity improved, 10 eyes had postoperative visual acuity equal or great than $0.1(20 / 200)$. The mean IOP at final visit was $15.7 \pm 4.2 \mathrm{mmHg}$, ranging from 10 to $28 \mathrm{mmHg}$.

Conclusions: Phacovitrectomy without preorerative steroids can achieve a satisfied single-operation anatomic and functional outcome. Free of preoperative steroid intervention will not only reduce the time waiting for surgery but also avoid the complications associated with systemic or local administration of steroids.

\section{Background}

Rhegamental retinal detachment associated with choroidal detachment(RRD/CD) is a rare condition characterized by severe inflamation and poor prognosis. ${ }^{1}$ Its overalll successful rate of retinal reattachment after single-operation has been significantly improved by primary vitrectomy and preoperative systemic administration of steroids[2,3]. Preoperative periocular /intravitreal triamicinolone injection was also reported to have comparative results as systemic adminstration[4]. However, Denwattana et al[5]revealed that although preoperative steroid significantly improved CD before vitrectomy, but seemed not to improve the singleoperation retinal reattachment rate or visual acuity at 3 months when compared to no steroid treatment in RRD/CD patients. Some studies demonstrated that combined lensectomy or lens extraction can improve anatomical reattachment rates in patients with $\mathrm{RRD} / \mathrm{CD}[3,6,7]$. Since 2015, we routinely treated these patients with phaco plus micro-invasive vitrectomy(phacovitrectomy) without preoperative administration of steroids, and obtained a satisfied results.

\section{Methods}

We retrospectively reviewed the medical records of all the patients who underwent phacovitrectomy for RRD/CD from June 2014 to March 2018. Preoperative Choroidal detachment(CD) was diagnosed by either 
indirect ophthalmoscopic examination or B-scan ultrasonography. Exclusion criteria included the following: recurrent retinal detachment; history of previous ocular surgery; history of ocular trauma; and a follow-up of < 3 months. Patients who had the ciliary detachment alone detected by UBM without concomitant choroidal detachment on $B$ ultrasound were aslo excluded from the study. The $C D$ was categorized as mild if shallow peripheral choroidals were present, severe if the $C D$ reached up to the equator, and moderate if it was of intermediate extent according to Sharma et al[8]. Information for each case record included age, gender, initial visual acuity, initial intraocular pressure, surgical procedures, retina status (detached or attached), final visual outcome and intraocular pressure. The extent of preoperative ciliary detachment were classified as mild, moderate and severe by the angle measured on UBM according to the method described by Li[9]. This study adhered to the tenets of the Declaration of Helsinki and was approved by the Ethics Committee of Chongqing Aier-Mega Eye Hospital. Informed written consent was obtained from each patient before surgery.

\section{Surgical technique}

All the patients received phaco and transconjunctival sutureless micro-invasive vitrectomy. Prior to phaco, a 25 $\mathrm{G}$ or $23 \mathrm{G}$ trocar was inserted inferior-temporally. If the introcular pressure was too low to ensure a successful insertion of trocar, intravitreal injection of saline solution can be performed with $1 \mathrm{cc}$ needle to raise the introcular pressure before insertion of the trocar. Make sure the cannula within the vitreous cavity before initiating the irrigation. Trocar in either superior temporal or nasal quadrant was inserted just beneath the scleral to drain the fluids of suprachoroidal space. The eyeball can be squashed by cotton swab to help draining of supper-choroid fluid and then stop irrigation. After parenthesis, a $2.2 \mathrm{~mm}$ clear corneal or corneoscleral tunnel incision was made. If the anterior chamber is very deep, then drain some fluid through corneal incision till the depths of anterior chamber become a little shallow. Viscoat is injected to flatten the surface of anterior capsular. As zonular was usually loosen, capsulorrhexis was done by either needle or forcep with gentle. The rest procedure is similar to routine cataract procedure except that no introcular lens were implanted. After completion of cataract operation, vitrectomy was performed under wide angle viewing system. The superior nasal and temporal trocar shall be reinserted to ensure the trocar is within the vitreous cavity. Vitreous was then removed thoroughly, retina was reattached with the aid of perfluorocarbon liquid or by air fluid exchange, retinal tear or hole were closed by laser photocoagulaion, Silicone oil was filled after gasfluid exchange. No scleral buckle or encircling procedure was performed,

\section{Results}

Seventeen patients ( 17 eyes), 8 women and 9 men, met the including criteria with mean age of $60.4 \pm 8.4$ years. Their preoperative epidemiological data and postoperative outcomes were listed on table1. Preoperative $B$ ultrasound showed that choroidal detachment was severe in 10 eyes (58.8\%), moderate in 2 eyes (11.8\%)and mild in 5 eyes(29.4\%). Fifteen eyes which had also preoperative UBM examined showed ciliary body detachment was severe in 12 eyes(80.0\%), mild in 3 eyes(20.0\%). $77.7 \%(7 / 9)$ of the eyes classified as severe choroidal detachment had also severe ciliary body detachment. Case 7 and 16 had severe choroidal detachment but had only mild ciliary body detachment, while case 5,11 and 13 had severe ciliary body detachment but presented with only mild choroidal detachment. 
Phaco was accomplished uneventfully in all eyes with posterior capsular contact except one eye (case1) who had a ruptured posterior capsular and had ando hole performed. Postoperative anterior chamber was generally quiet without significant posterior synechiae. Fifteen eyes(82.4\%) had retina reattached after single operation. Of these 15 eyes, 14 eyes had SO removed, 8 of them had intraocular lens implanted, 2 eye had epimacular membrane peeling at the time of removing SO. One eye(case 16) was refilled with SO after membrane peeling for the safety because of its fixed retinal folds was so rigid. Another eye( case 15) was treated with encircling procedure to cure new hole found at the time of SO removing. Two patients (case 7 and case 10) had retinal redetached within a month after primary surgical repair. These two cases would not willing to take re-operation. Fifteen eyes had postoperative visual acuity improved, 10 eyes had postoperative visual acuity equal or great than $0.1(20 / 200)$. The mean IOP at final visit was $15.7 \pm 4.2 \mathrm{mmHg}$, ranging from 10 to $28 \mathrm{mmHg}$.

\section{Discussion}

The incidence of combined retinal detachment with associated choroidal detachment is reported about 28.6\%[10-12]. Li et al[9].revealed that proportion of RRD/CD can be as high as $18.7 \%$ among RRD patients when diagnosed by UBM. Although UBM can help detecting mild choroidal detachment which may be missed out on B ultrasound examination, ciliary body detachment alone may account for a large proportion of this higher incidence. Our previous study showed 1/4 of RRD had cilary body detachment detected by UBM without concurrent choroidal detachment on B ultrasound examination, but ciliary body detachment alone did not differ from those patients without cilary body detachment in both anatomic reattachment rate and postoperative visual acuity improvement(in Chinese). So in our current retrospective study, ciliary body detachment alone was not included. The relationship between the severity of ciliary body detachment and choroidal detachment is somewhat puzzling. Although in those eyes classified as severe choroidal detachment, the majority had also severe ciliary body detachment, eyes with severe choroidal detachment can present with mild ciliary body detachment while eyes with severe ciliary body detachment may had only mild choroidal detachment.

Our case series observation demonstrated that $82.4 \%$ of retinal reattachment rate after single operation can be achieved in the absence of preoperative steroids intervention. Though one case was refilled with SO after membrane peeling, he is still regarded as successful case after single operation. The reason for refilling SO is just for the safety as the retinal was still uneven after membrane peeling. Postoperative follow-up showed the retina was well attached without any visible retinal tear or hole. Even this case was not inclued in the single operation success list, this result is still comparable to those reports with preoperative steroids, that is from $51 \%$ to $81.8 \%[2,3,5,8,13-15]$. Because of the severe inflammation throughout the course of the disease in patients with RRD/CD, many researchers believed that preoperative administration of steroids could benefit the surgical outcome. Literature search showed that most of these studies mainly evaluated the effects of preoperative administration of steroids between different routes: systemic or periocular or intravitreal administration. But only two of these studies compared the effects of preoperative steroids to steroids-sparing treatment, and they showed contradict results [2,5] Study conducted by Denwattana et al [5] disclosed that preoperative steroid treatment can significantly improved CD before vitrectomy, but seemed not to improve the single-operation retinal reattachment rate or visual acuity at 3 months when compared to no steroid treatment 
in RRD/CD patients. It seems that although preoperative steroids can help controlling inflammation, it may be not as so important as we once thought. We think the quickest way to control the inflammation shall be established in the prompt reattachment of the detached retina, thus completely breaking the vicious cycle in $\mathrm{RRD} / \mathrm{CD}$.

studies showed eyes left phakic at the completion of surgery may have a lower rate of anatomical success when compared with eyes rendered aphakic or pseudophakic, and the proportion of postoperative hypotony was also lower in those eyes that were aphakic after surgery when compared with those eyes that were nonaphakic[6,7]. Our previous report also demonstrated that lensectomy+vitrectomy+silicone oil tamponade offered better result in patients with RRD/CD , as this allowed more thorough cleavage of peripheral vitreous,leaving more space for the fill of SO[3]. Recently , $\mathrm{Xu} \mathrm{H}$, et al[16]found that $23 \mathrm{G}$ PPV+phaco+capsulotomy without IOL implantation had a significantly higher reattachment rate (78\%) than 23G PPV+phaco +IOL implantation (40\%) in treating RRD/CD. We think primary IOL implantation may aggregate the already severe inflammation in this disease entities, thus reducing the surgical outcomes. Our current series observation showed combined phacovitrectomy without IOL implantation had similar results as those reported by Xu and Gui[3,16 ]. Phacovitrectomy seems more efficient than combined vitrectomy and lensectomy and reserved the advantage of micro-invasive vitrectomy. When doing the phaco, it seems more easily to keep an intact posterior capsular bag, thus, reducing the necessity of performing an ando hole. Phacovitrectomy can remove opacified lens to make a better viewing of the fundus when there is an already existed cataract. Even though the lens are temporary clear, cataract will eventually progress after vitrectomy with gas or SO tamponade and cataract surgery after vitrectomy becomes complex[17]. When eye is aphakic, it also gives a more wider viewing of fundus after gas-fluid exchange under wide angle viewing system, making peripheral photocoagulation more convenient.

\section{Conclusions}

With the widespread application of some new technologies such as micro-invasive vitrectomy under wide angle viewing system, photocoagulation rather than cryotherapy and SO tamponade rather than gas, our case series demonstrated that an acceptable anatomical and functional results can be achieved by phacovitrectomy without preoperative steroids for RRD/CD, thus reducing the time waiting for surgery and avoiding the complications associated with systemic or local administration of steroids. Due to the small number observed in our case series and its retrospective non-controlled study, a prospective, multi-centered, randomized controlled study is needed to further explore the role of phacovitrectomy and necessity of preoperative steroids application for the treatment of RRD/CD.

\section{Declarations}

\section{Ethics approval and consent to participate}

This study was approved by the Ethics Committee of Chongqing Aier-Mega Eye Hospital and consent to participate.

\section{Consent for publication}


The Ethics Committee of Chongqing Aier-Mega Eye Hospital waived the necessity of obtaining written or verbal consent from patients for publication.

\section{Funding}

No funding was obtained for this study

\section{Acknowledgements}

Not Applicable

\section{Availability of data and materials}

The datasets used and/or analysed during the current study available from the corresponding author on reasonable request.

\section{Competing interests}

None of the authors have any financial or proprietary interest in any product mentioned.

\section{Authors' contribution}

JG made a substantial contribution to conception and design, analysis and interpretation of data, drafting the manuscript and revising it critically for important intellectual content. LA and TH were involved in study conception and design and analysis and interpretation of data. All authors read and approved the final manuscript.

\section{References}

1. Jarrett WH 2nd.Rhematogenous retinal detachment complicated by severe intraocular inflammation, hypotony, and choroidal detachment. Trans Am Ophthalmol Soc. 1981;79:664-83.

2. Sharma T, Gopal L, Reddy RK, Kasinathan N, Shah NA, Sulochana KN, Miriam KC, Arvind K, Ramakrishnan S, Sukumar B. Primary vitrectomy for combined rhegmatogenous retinal detachment and choroidal detachment with or without oral corticosteroids: a pilot study. Retina. 2005;25(2):152-157.

3. Gui JM, Jia L, Liu L, Liu JD. Vitrectomy, lensectomy and silicone oil tamponade in the management of retinal detachment associated with choroidal detachment. International journal of ophthalmology. 2013;6(3):337-341.

4. Mao JB, Wu SL, Chen YQ, Dong YG, Zheng B, Tao JW, Zhao SX, Fang D, Shen LJ. The efficiency of 23 G vitrectomy combined with preoperative subtenon injection of triamcinolone acetonide for treatment of retinal detachment associated with choroidal detachment]. [Zhonghua yan ke za zhi] Chinese journal of ophthalmology. $2018 ; 54(4): 252-257$ 
5. Denwattana A, Prakhunhungsit S, Thoongsuwan S, Rodanant N, Phasukkijwatana N. Surgical outcomes of preoperative steroid for rhegmatogenous retinal detachment with associated choroidal detachment. Eye. 2018;32(3):602-607.

6. Tseng JJ, Schiff WM, Barile GR, Biscette O, Williams SL, Cekic O, Dhrami-Gavazi E, Chang S. Influence of postoperative lens status on intraocular pressure in proliferative vitreoretinopathy. American journal of ophthalmology. 2009;147(5):875-885, 885 e871-872.

7. Caiado RR, Magalhaes O, Jr., Badaro E, Maia A, Novais EA, Stefanini FR, Navarro RM, Arevalo JF, Wu L, Moraes N, Farah ME, Maia M. Effect of lens status in the surgical success of 23-gauge primary vitrectomy for the management of rhegmatogenous retinal detachment: the Pan American Collaborative Retina Study (PACORES) group results. Retina. 2015;35(2):326-333.

8. Sharma T, Gopal L, Badrinath SS. Primary vitrectomy for rhegmatogenous retinal detachment associated with choroidal detachment. Ophthalmology. 1998;105(12):2282-2285.

9. Li Z, Li Y, Huang X, Cai XY, Chen X, Li S, Huang Y, Lu L. Quantitative analysis of rhegmatogenous retinal detachment associated with choroidal detachment in Chinese using UBM. Retina. 2012;32(10):2020-2025.

10. Gottlieb F. Combined choroidal and retinal detachment. Archives of ophthalmology. 1972;88(5):481-486.

11. Seelenfreund MH, Kraushar MF, Schepens CL, Freilich DB. Choroidal detachment associated with primary retinal detachment. Archives of ophthalmology. 1974;91(4):254-258.

12. Yu Y, An M, Mo B, Yang Z, Liu W. Risk factors for choroidal detachment following rhegmatogenous retinal detachment in a chinese population. BMC ophthalmology. 2016;16:140.

13. 13. Loo A, Fitt AW, Ramchandani M, Kirkby GR. Pars plana vitrectomy with silicone oil in the management of combined rhegmatogenous retinal and choroidal detachment. Eye. 2001;15(Pt 5):612-615.

14. 14. Ghoraba HH. Primary vitrectomy for the management of rhegmatogenous retinal detachment associated with choroidal detachment. Graefe's archive for clinical and experimental ophthalmology. 2001;239(10):733-736.

15. 15. Wei Y, Wang N, Chen F, Wang H, Bi C, Zu Z, Yang X. Vitrectomy combined with periocular/intravitreal injection of steroids for rhegmatogenous retinal detachment associated with choroidal detachment. Retina. 2014;34(1):136-141.

16. 16. Xu H, Lutrin $\mathrm{D}$, Wu Z. Outcomes of 23-gauge pars plana vitrectomy combined with phacoemulsification and capsulotomy without intraocular lens implantation in rhegmatogenous retinal detachment associated with choroidal detachment. Medicine (Baltimore). 2017;96(1):e7869. 
17. 17. Cole CJ, Charteris DG. Cataract extraction after retinal detachment repair by vitrectomy: visual outcome and complications. Eye. 2009;23(6):1377-1381.

\section{Tables}

Table 1. Epidemiological characteristics of preoperative RRD/CD patients treated with phacovitrectomy

\begin{tabular}{|c|c|c|c|c|c|c|c|c|c|}
\hline Case & $\begin{array}{l}\text { Sex/Age- } \\
\text { ramges/other }\end{array}$ & $\begin{array}{l}\text { Grade of } \\
\text { Ciliary } \\
\text { body } \\
\text { detachment }\end{array}$ & $\begin{array}{l}\text { Grade of } \\
\text { choroidal } \\
\text { Detachment }\end{array}$ & $\begin{array}{l}\text { Initial } \\
\text { VA }\end{array}$ & $\begin{array}{l}\text { Final } \\
\text { VA }\end{array}$ & $\begin{array}{l}\text { Inital/Final } \\
\text { IOP }\end{array}$ & $\begin{array}{l}\text { Follow- } \\
\text { up(M) }\end{array}$ & $\begin{array}{l}\text { Anatomic } \\
\text { outcome } \\
\text { after } \\
\text { single } \\
\text { operation }\end{array}$ & Comments \\
\hline 1 & $\begin{array}{l}\text { F/60-69/high } \\
\text { myopia }\end{array}$ & NA & severe & $\mathrm{FC}$ & 0.1 & $4 / 12$ & 48 & attached & SO removed \\
\hline 2 & $\begin{array}{l}\text { F/60- } \\
69 / \mathrm{EMM}\end{array}$ & NA & Mild & 0.02 & 0.3 & $12 / 28$ & 9 & attached & $\begin{array}{l}\text { SO removed, } \\
\text { IOL } \\
\text { implanted }\end{array}$ \\
\hline 3 & $\begin{array}{l}\text { M/60-69/old } \\
\text { RRD }\end{array}$ & Severe & Severe & $\mathrm{HM}$ & 0.05 & $8 / 11$ & 15 & attached & SO removed \\
\hline 4 & $\mathrm{~F} / 50-59$ & Severe & Severe & 0.04 & 0.3 & $15 / 12$ & 8 & attached & $\begin{array}{l}\text { SO removed, } \\
\text { IOL } \\
\text { implanted }\end{array}$ \\
\hline 5 & $\begin{array}{l}\text { M/70- } \\
\text { 79/MHRD }\end{array}$ & Severe & Mild & 0.04 & 0.04 & $9 / 18$ & 8 & attached & SO removed \\
\hline 6 & M/60-69 & Severe & Moderate & 0.1 & 0.25 & $3.7 / 10$ & 10 & attached & $\begin{array}{l}\text { SO removed, } \\
\text { IOL } \\
\text { implanted }\end{array}$ \\
\hline 7 & $\mathrm{~F} / 50-59$ & Mild & Severe & FC & 0.1 & $10 / 15$ & 8 & detached & retained SO \\
\hline 8 & $\begin{array}{l}\text { M/40- } \\
\text { 49/High } \\
\text { myopia }\end{array}$ & Severe & Severe & HM & 0.2 & 6/17 & 10 & attached & $\begin{array}{l}\text { SO removed, } \\
\text { IOL } \\
\text { implanted }\end{array}$ \\
\hline 9 & $\mathrm{~F} / 60-69$ & Severe & Moderate & 0.1 & 0.15 & $8 / 16$ & 10 & attached & SO retained \\
\hline 10 & $\mathrm{~F} / 50-59$ & Severe & Severe & $\mathrm{HM}$ & 0.05 & $8 / 15$ & 6 & detached & SO retained \\
\hline 11 & $\begin{array}{l}\text { F/50- } \\
\text { 59/MHRD }\end{array}$ & Severe & Mild & 0.02 & FC & $3 / 17$ & 8 & attached & $\begin{array}{l}\text { SO } \\
\text { removed+IOL } \\
\text { implanted }\end{array}$ \\
\hline 12 & M/60-69 & Severe & Severe & $\mathrm{HM}$ & 0.15 & $3 / 17$ & 8 & attached & $\begin{array}{l}\text { SO removed, } \\
\text { EMM peeled, } \\
\text { IOL } \\
\text { implanted }\end{array}$ \\
\hline 13 & $\begin{array}{l}\text { M/60- } \\
\text { 69/MHRD }\end{array}$ & Severe & Mild & 0.02 & 0.06 & $8 / 20.5$ & 7 & attached & SO removed \\
\hline 14 & M/60-69 & Severe & severe & HM & 0.4 & $7 / 14$ & 7 & attached & SO removed \\
\hline 15 & $\mathrm{M} / 70-79$ & Severe & Severe & HM & 0.05 & $12 / 14$ & 4 & attached & $\begin{array}{l}\text { SO removed, } \\
\text { cryo, encircle }\end{array}$ \\
\hline 16 & M/60-69 & Mild & Severe & $\mathrm{HM}$ & FC & $5 / 13$ & 4 & attached & $\begin{array}{l}\text { SO removed, } \\
\text { mem peeled, } \\
\text { refilled with } \\
\text { SO }\end{array}$ \\
\hline 17 & $\begin{array}{l}\text { F/30-39/High } \\
\text { myopia }\end{array}$ & Mild & Mild & FC & 0.15 & $7 / 18$ & 5 & attached & $\begin{array}{l}\text { SO removed, } \\
\text { IOL } \\
\text { implanted }\end{array}$ \\
\hline
\end{tabular}

Abbreviations:EMM, epi-macular membrane; FC, finger counting; HM, hand motion; IOL, intraocular lens; MHRD, retinal detachment associated with macular hole;SO, silicone oil; 
Page 9/9 